\title{
THE POTENTIOMETRIC MEASUREMENT OF THE RESTING POTENTIAL OF FROG MUSCLE FIBERS
}

\author{
Hiroshi KiTA
}

Department of Physiology, School of Medicine, Juntendo University, Hongo, Tokyo

The measurement of resting potential has been made by a number of workers on various tissues, especially since the introduction of micro-electrode techniques (see reviews: HodGKIN, 1951, 1958 ; Shanes, 1958). These investigations are generally classified into two types; measurements with external electrodes and those with internal electrodes. It is well-known that the most satisfactory way of measuring the electrical potential difference is to use a potentiometric, i.e., compensating method. Although many investigations have been carried out on the resting potential, there are only a few papers describing the measurement of resting potential with the compensating method. This method is sometimes used in the studies on the resting potential with external electrodes (RothschuH, 1950; HuXLEy and STÄMPFLI, 1951), but in this case great caution must be exercised about the short-circuiting effect of the external fluid between two electrodes, usually one on a normal region of the tissue, the other on a region damaged chemically or by crushing. The magnitude of the resting potential so obtained.(demarcation potential) seems to be lower than that obtained with internal electrodes. For example, RotHScHuH (1950) obtained $-55 \mathrm{mV}$ (internal potential with reference to the external fluid) as the initial value of the resting potential (he observed the time course of the changes in the resting potential for many hours) by measuring the potential difference between normal and injured regions of the frog sartorius muscle. In a frog myelinated nerve fiber, HUXLEY and STÄMPFLI (1951) measured the potential difference between a normal node and one blocked with isotonic $\mathrm{KCl}$ solution and found a value of $-67.6 \pm 1.4 \mathrm{mV}$ (S. E. of mean, blocked node negative). Moreover, STÄMPFLI (1954) obtained about $-70 \mathrm{mV}$ in a bundle of myelinated nerve fibers of a frog using the sucrose gap technique.

Since the recent development of methods for intracellular potential recording, the measurement of resting potential has become easier to carry out and been performed more extensively in a great variety of living tissues than

Received for publication August 3, 1965.

* 喜多 弘, Present address: Department of Sport Physiology, School of Physical Education, Juntendo University, Narashino, Chiba, Japan. 
before. When the micro-electrodes are used, the short-circuiting effect of the external fluid around them would be neglected. Of many investigations on the resting potential of nerve and muscle with internal electrodes, the main works on frog sartorius fibers are as follows: LING and GERARD (1949) obtained $-78.4 \pm 5.3 \mathrm{mV}$, NASTUK and HoDGKIN (1950) found the average resting potential of $-88 \mathrm{mV}$ at $18^{\circ} \mathrm{C}$ and ADRIAN (1956) obtained $-92.2 \pm 0.5 \mathrm{mV}$ paying attention to the electrode tip potential. In the experiments by HoDGKIN and Horowicz (1959) on single muscle fibers, it was shown that the mean value of resting potential was about $-94 \mathrm{mV}$. These measurements with internal electrodes, however, were not performed by the potentiometric procedure.

Although the potentiometric method should be the most preferable one for the measurement of the magnitude of the intracellularly detected resting potential, few works have adopted the combined method of intracellular micro-electrodes and the potentiometry. In the present experiments the magnitude of the resting potential of the frog sartorius fibers was determined by the compensating method using two Ling-Gerard type micro-electrodes, one of which was inserted into the fiber and the other placed in the external fluid, and a current sensitive galvanometer as a null instrument. The time course of the change in the resting potential was also observed for several hours.

A preliminary account of the experiments described here was given at the 38th annual meeting of the Physiological Society of Japan held in April, 1961 at Kyoto (SAKamoto, Kita and Kurosawa, 1961).

\section{METHODS}

Material. Sartorius muscles of well-fed Japanese frogs (Rana nigromaculata) were used throughout the investigation. When the muscle was mounted in a Ringer bath, it was stretched to about $130 \%$ of its slack length.

Solution. The composition of Ringer's solution used in the present investigation was as follows: $\mathrm{NaCl} 111.2 \mathrm{mM} ; \mathrm{KCl} 2.0 \mathrm{mM} ; \mathrm{CaCl}_{2} 1.8 \mathrm{mM} ; \mathrm{NaHCO}_{3} 2.4 \mathrm{mM}$; $\mathrm{NaH}_{2} \mathrm{PO}_{4} 0.06 \mathrm{mM}$.

Micro-electrodes. A pair of similar glass micro-electrodes (Ling and Gerard, 1949; NAstuk and Hodgkin, 1950), filled with $3 \mathrm{M}-\mathrm{KCl}$ (sometimes $3 \mathrm{M}-\mathrm{NaCl}$ ) and had a resistance of $10-20 \mathrm{M} \Omega$ (10 $\mathrm{M} \Omega$ was the best suited to this work) were used for measuring the resting potential, one of which served as an internal electrode and the other as an external electrode. A fine silver wire was inserted into a micro-electrode.

Electrical apparatus. The experimental arrangement is shown in Fig. 1. All the switches used were manually operated switches with mercury contacts. Two resistors $\left(W_{1}\right.$ and $W_{2}$ in Fig. 1) for the voltage compensation were resistance boxes operated by rotary contacts (Yokogawa Electric Works). $W_{1}$ was variable from 1 to $11,111 \Omega$ in steps of $1 \Omega$ and had a linear resistance against frequencies ranging 0 to $800 \mathrm{KC}$, while $W_{2}$, from 0.1 to $1,111 \Omega$ in steps of $0.1 \Omega$ and 0 to $10 \mathrm{MC}$. When compensating voltages were applied, $W_{1}$ was fixed at a value of $10^{4} \Omega$ and $W_{2}$ was varied. At the larger value of $W_{2}$ the higher compensating voltage was obtained. A ballistic galvano- 


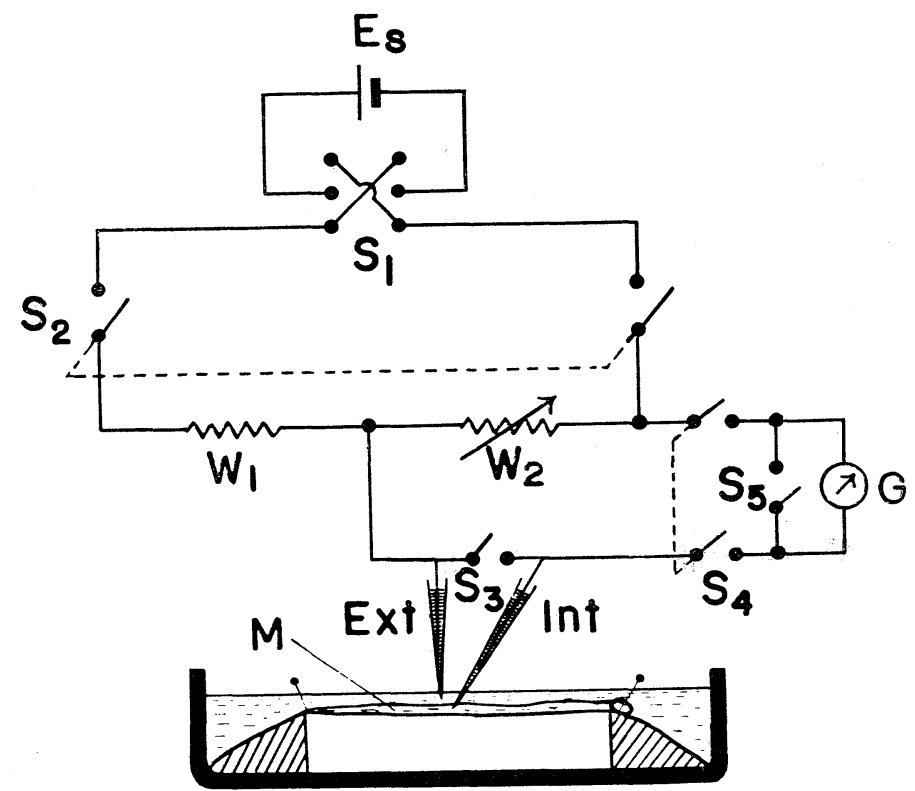

FIG. 1. Simplified diagram showing the method of measuring resting potential by potentiometric procedure with two micro-electrodes. $M$, sartorium muscle; Ext, external electrode; Int, internal electrode; $W_{1}$, resistor $\left(10^{4} \Omega\right) ; W_{2}$, variable resistor $(0.1-1,111 \Omega) ; G$, ballistic galvanometer; $E_{s}$, battery $(2 \mathrm{~V})$ to supply compensating current; $S_{1}-S_{5}$, switches: $S_{1}$, for reversing polarity of compensating current; $S_{2}$, for voltage application; $S_{3}$, for shunting both electrodes; $S_{4}$, for leading compensating current to the galvanometer; $S_{5}$, for shunting the galvanometer.

meter (Yokogawa Electric Works) with lamp and scale was used as a null instrument: $1 \mathrm{~mm}$ of the scale corresponding to $4.14 \times 10^{-11} \mathrm{~A}$. The galvanometer was set on a shock-absorbing rack. The scale was $500 \mathrm{~mm}$ in length bilaterally. Scales on the right hand in the visual field of the telescope was read as positive.

In order to eliminate electrical disturbances, all the experiments were performed in a shield room made of copper meshes grounded with a resistance of $1.3 \Omega$ and the very high degree of insulation was met by polystyrol plates allowing a resistance of more than $1,000 \mathrm{M} \Omega$ between the apparatus and the floor of the room. During the measurement all the $\mathrm{AC}$ sources of the room were turned off and electric sources for illumination were supplied from batteries.

Experimental procedure. The battery voltage $E_{s}$ was checked at the beginning and the end of each experiment. When $E_{s}$ dropped during the experiment (usually not exceeding $0.1 \mathrm{mV}$ ), the mean value at the beginning and the end of the experiment was taken. After the muscle was mounted in the Ringer bath and the electrode tips were immersed in the Ringer with the aid of micromanipulators, both electrodes were shunted by closing switch $S_{3}$ in order to reduce the potential difference appeared between them ("electrode potential"), while all other switches were kept open. In order to determine the zero point of the galvanometer, the input of the galvanometer was. opened (switches $S_{4}$ and $S_{5}$ were opened). After swings of the mirror attached to the coil of the galvanometer ceased, the zero line of the scale was adjusted to fall on the 
standard line within the visual field of the telescope. Thereafter, the "electrode potential" was measured by means of the compensating method, the detail of which would be described in 'Results'. When the deflection of the galvanometer showed. positive, the internal electrode should be negative to the external one. The reading of the galvanometer deflection, i. e., the equilibrium position of the galvanometer swing (l) was obtained by the following way (swing method). Three successive tropical points of the swing $\left(l_{1}, l_{2}\right.$ and $l_{3}$ respectively) were read and then $l$ was simply determined by the following formula (KoHLRAusch, 1927),

$$
l=1 / 4\left(l_{1}+2 l_{2}+l_{3}\right) .
$$

A $1 \mathrm{~mm}$ scale was read up to $1 / 10$ of it $\left(0.1 \mathrm{~mm}\right.$ corresponded to $\left.4.14 \times 10^{-12} \mathrm{~A}\right)$. In order to apply a compensating voltage, the position of switch $S_{1}$ was set so that the compensating voltage opposed the voltage to be measured and then switches $S_{2}$ and $S_{4}$ were closed. successively, while switches $S_{3}$ and $S_{5}$ were kept open. When the "electrode potential" exceeded about $15 \mathrm{mV}$, either or both of the electrodes were renewed. Electrodes having the same resistance were selected since the asymmetry in electrode resistances caused relatively large "electrode potential". According to ADRIAN (1956), the correlation between tip potential and micro-electrode resistance was -0.766 and significant $(P<0.01)$. After checking the "electrode potential" the internal electrode was inserted transversely into the fiber under the control of a binocular microscope $(\times 60)$ and only the switch $S_{4}$ was closed. The insertion of the electrode was confirmed by the positive deflection of the galvanometer showing that the interior of the cell was negative to the exterior. The inserted micro-electrode was left inside the fiber for four hours during which the resting potential was measured every fifteen minutes for two hours and thereafter every thirty minutes. At the end of the measurement, the internal electrode was withdrawn and the "electrode potential" was checked again.

The experiments were performed between July and December at room temperature $\left(18.7-30.4^{\circ} \mathrm{C}\right)$.

\section{RESULTS}

The measurement of the "electrode potential". There should be no potential difference between two micro-electrodes measuring the resting potential, but it was difficult to obtain satisfactory ones. Therefore, the "electrode potential" was measured before the measurement of the resting potential was started. After the electrode tips were immersed in the Ringer, $S_{3}$ and $S_{5}$ were kept open while $S_{4}$ closed and the magnitude of the galvanometer deflection was checked in the condition without applying any compensating voltage. The compensating voltage was adjusted by $W_{2}$, the resistance of which was several ten ohms. Since the perfect compensation could not be obtained at one trial, the compensation was made and following three deflection points were recorded together with corresponding values of $W_{2}$ : (a) a point that the compensation was deficient, (b) nearly made and (c) excessive. If these points did not fall on a straight line when deflections were plotted against values of $W_{2}$, the measurement must be repeated. When a straight line was drawn through the points, the value of $W_{2}$ at the perfect compensa- 


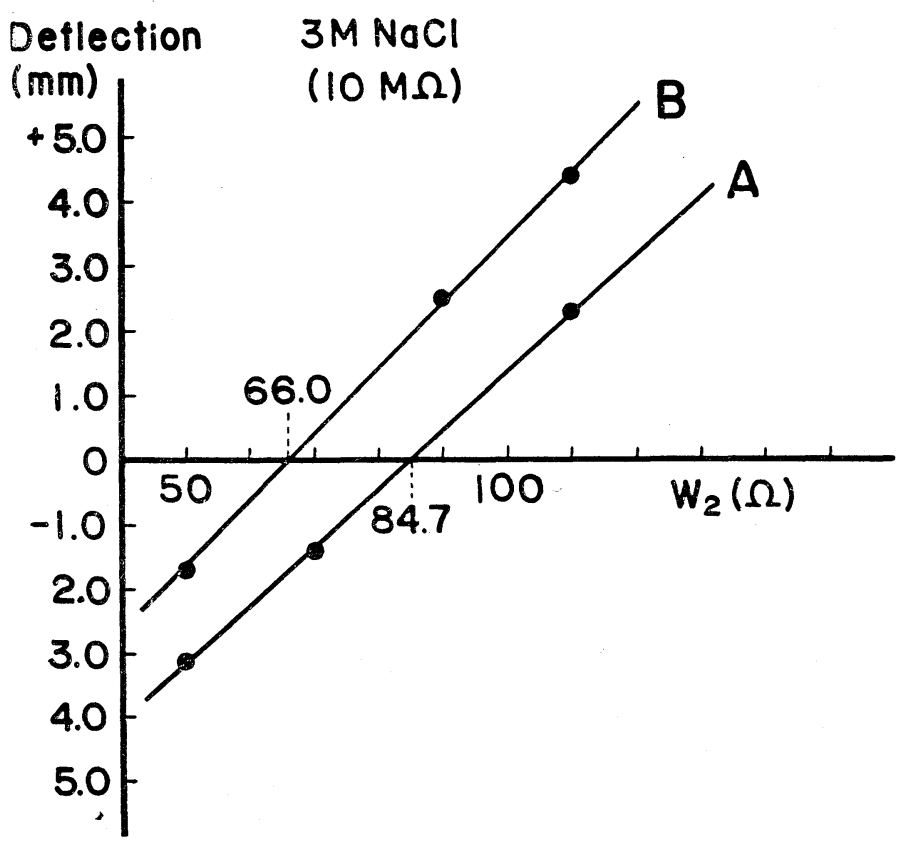

FIG. 2. Determination of the value of $W_{2}$ by straight interpolation in "electrode potential" measurement. Ordinate : galvanometer deflection in $\mathrm{mm}$ read by the swing methed. Abscissa: value of $W_{2}$ in $\Omega$. The value of $W_{2}$ at the perfect compensation is obtained as a point at which the straight line throughout the three points (see Text) intersects the abscissa. In this instance, two $3 \mathrm{M}-\mathrm{NaCl}$ filled micro-electrodes (resistance : $10 \mathrm{M} \Omega$ each) were used and the " electrode potentials" before and after the experiment $\left(E_{e}{ }^{\prime}\right.$ and $E_{e}{ }^{\prime \prime}$ respectively) were calculated. Straight line $A$ : before experiment, $B$ : after experiment. Taking $E_{s}=2.10 \mathrm{~V}, W_{1}=10^{4} \Omega$ and $W_{2}$ for $A$ $=84.7 \Omega$ and for $B=66.0 \Omega$, so $E_{e}{ }^{\prime}=17.64 \mathrm{mV}$ and $E_{e}{ }^{\prime \prime}=13.77 \mathrm{mV}$. Thus the "electrode potential", $E_{e}=E_{e}{ }^{\prime}+E_{e}{ }^{\prime \prime} / 2=15.71 \mathrm{mV}$ was obtained.

tion was obtained at the intersection of the straight line with the abscissa as shown in FIG. 2 (interpolation). The ascending line showed that the internal electrode was positive to the external one and the descending line negative. When the value of $W_{2}$ was thus obtained, the potential difference across the resistance of $W_{2}\left(E_{A B}\right)$ ("electrode potential" itself in this case) should be given by

$$
E_{A B}=\frac{W_{2}}{W_{1}+\bar{W}_{2}} \times E_{s}(V),
$$

where $W_{1}$ and $W_{2}$ were the values of $W_{1}$ and $W_{2}(\Omega)$ and $E_{s}$ was the battery voltage $(V)$. In the example shown in FIG. 2, "electrode potentials" before $\left(E_{e}^{\prime}\right)$ and after $\left(E_{e}^{\prime \prime}\right)$ the experiment were found to be $17.64 \mathrm{mV}$ and $13.77 \mathrm{mV}$ 
respectively. Thus the "electrode potential" $\left(E_{e}\right)$, i. e., the mean value of $E_{e}^{\prime}$ and $E_{e}$ ", was obtained to be $15.71 \mathrm{mV}$.

When the difference between $E_{e}^{\prime}$ and $E_{e}^{\prime \prime}$ exceeded about $15 \mathrm{mV}$ or $E_{e}^{\prime \prime}$ reversed its polarity to $E_{e}{ }^{\prime}$, results obtained with these electrodes were usually discarded. It was sometimes found that $E_{e}$ " grew to a certain value in spite of $E_{e}^{\prime}$ was zero, or conversely $E_{e}^{\prime \prime}$ fell to zero from a certain value of $E_{e}{ }^{\prime}$. Probably these changes would be resulted from the blocking of the electrode (ADRIAN, 1956).

The "electrode potential" should be added to or subtracted from the measured potential $\left(E_{M}{ }^{\prime}\right)$ regarding whether the polarity of the "electrode potential" was reverse to or coincident with the resting potential. Thus the resting potential $\left(E_{M}\right)$ was obtained.

Values of "electrode potential" are shown in TABLE 1.

TABLE 1.

"Electrode potentials" $\left(E_{e}\right)$. Except No. 10, internal and external electrodes of the same resistance were used. + or - in parentheses attached to values of $E_{e}$ indicates that $E_{e}$ must be added to or subtracted from the values of measured potentials $\left(E_{M^{\prime}}\right)$. Values of resting potentials $\left(E_{M}\right)$ immediately after the insertion are also listed. The average value of $E_{M}$ was $86.87 \pm 8.28 \mathrm{mV}$ (S.D.).

\begin{tabular}{|c|c|c|c|c|c|c|}
\hline \multicolumn{7}{|c|}{ Electrode } \\
\hline $\begin{array}{c}\text { Experiment } \\
\text { number }\end{array}$ & $\begin{array}{c}\text { Date } \\
(1960)\end{array}$ & $\mid \begin{array}{c}\text { Room } \\
\text { temperature } \\
\left({ }^{\circ} \mathrm{C}\right)\end{array}$ & $\begin{array}{l}\text { Filled } \\
\text { with }\end{array}$ & $\begin{array}{l}\text { Resistance } \\
\quad(\mathrm{M} \Omega)\end{array}$ & $\begin{array}{c}E_{e} \\
(\mathrm{mV})\end{array}$ & $\begin{array}{c}E_{M} \text { just after } \\
\text { insertion } \\
(\mathrm{mV})\end{array}$ \\
\hline 1 & 15 July & 28.6 & $3 \mathrm{M}-\mathrm{KCl}$ & 20 & $5.25(+)$ & 84.10 \\
\hline 2 & 22 July & 30.4 & $3 \mathrm{M}-\mathrm{NaCl}$ & 10 & $15.71(+)$ & 76.48 \\
\hline 4 & 26 Sept. & 27.4 & $3 \mathrm{M}-\mathrm{KCl}$ & 20 & $14.45(+)$ & 86.45 \\
\hline 5 & 30 Sept. & 25.3 & $3 \mathrm{M}-\mathrm{KCl}$ & 15 & $10.35(+)$ & 90.16 \\
\hline 7 & 7 Oct. & 22.8 & $3 \mathrm{M}-\mathrm{KCl}$ & 10 & $19.06(+)$ & 94.42 \\
\hline 8 & 10 Oct. & 22.4 & $3 \mathrm{M}-\mathrm{KCl}$ & 10 & $12.44(-)$ & 87.36 \\
\hline 9 & 9 Oct. & 22.5 & $3 \mathrm{M}-\mathrm{KCl}$ & 15 & $3.04(-)$ & 91.52 \\
\hline 10 & 14 Oct. & 22.4 & $3 \mathrm{M}-\mathrm{KCl}$ & $\begin{array}{r}15 \text { (Int.) } \\
5 \text { (Ext.) }\end{array}$ & $4.15(-)$ & 80.12 \\
\hline 11 & 21 Oct. & 22.5 & $3 \mathrm{M}-\mathrm{KCl}$ & 7 & $22.21(+)$ & 103.60 \\
\hline 12 & 18 Nov. & 18.7 & $3 \mathrm{M}-\mathrm{NaCl}$ & 20 & 0 & 74.46 \\
\hline
\end{tabular}

The measurement of the resting potential. The resting potential was measured in the same way as in determining the "electrode potential". The portion of electrode insertion was near the pelvic end that was away from the motor nerve entry to the muscle fiber. The external electrode was placed as near the internal electrode as possible and the potential difference across the membrane was obtained without reference to the ground.

In the case of resting potential measurement, $W_{2}$ was varied to $200 \Omega$ 
(deficient compensation), about $300 \Omega$ (nearly compensated) and $400 \Omega$ (excessive compensation) in order to obtain the three points for the interpolation and it took at least about 2.5 minutes for this procedure. The compensating current was of the order of $10^{-10} \mathrm{~A}$. FIG. 3 shows an example of the measurement with the same electrodes as those in FIG. 2. In FIG. 3, five straight

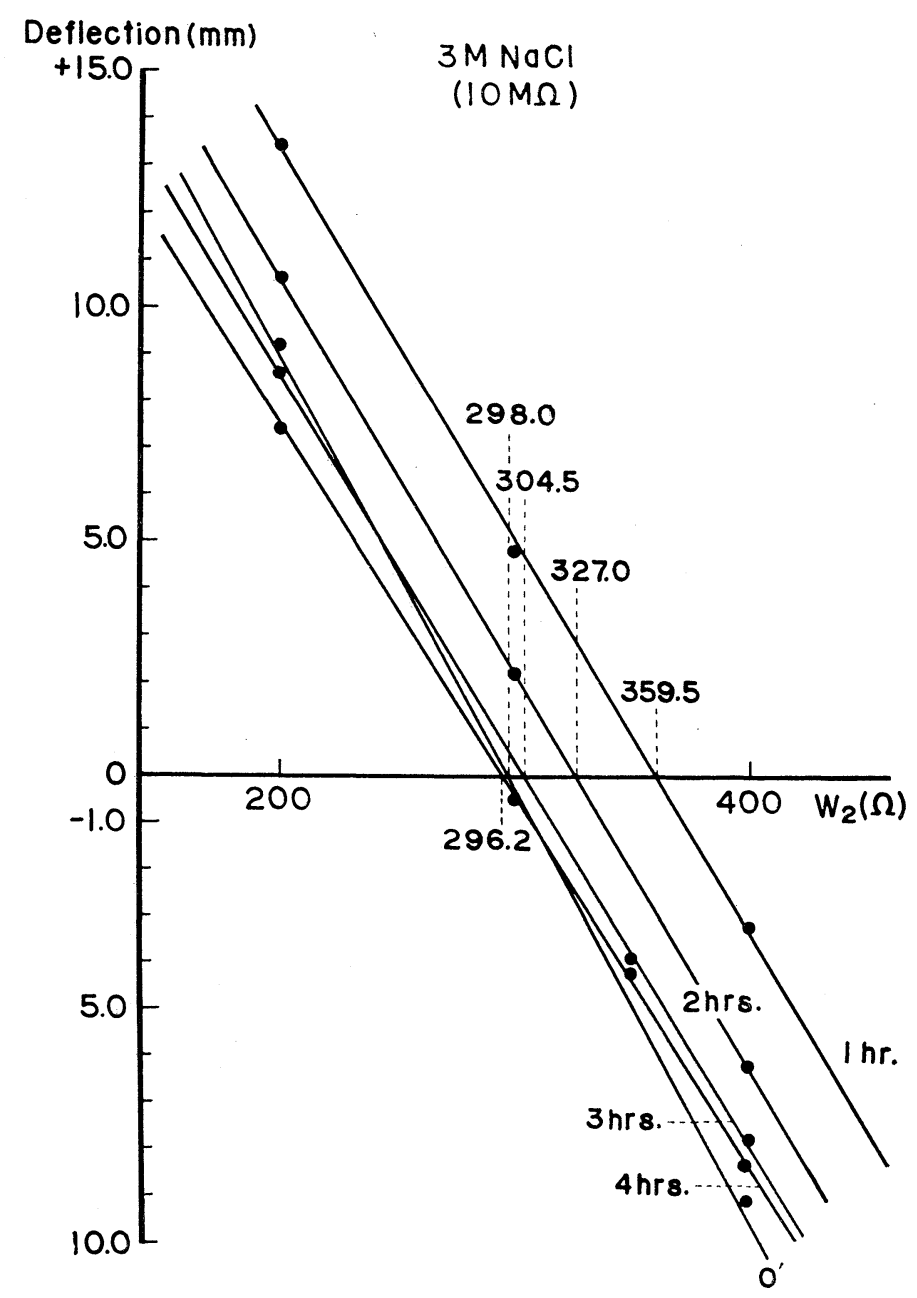

FIG. 3. Determination of the value of $W_{2}$ by straight interpolation in resting potential measurement. Ordinate: galvanometer deflection (mm). Abscissa: $W_{2}(\Omega)$. Electrodes used were the same as those in Fig. 2. Five straight lines give values of $W_{2}$ at $0,1,2,3$ and 4 hours after the insertion of the electrode, providing measured potentials $\left(E_{M^{\prime}}\right)$ of $60.77,72.88,66.50,62.06$ and $60.41 \mathrm{mV}$ respectively, to which the "electrode potential" of 15.71 $\mathrm{mV}$ (see FIG. 2.) must be added to obtain membrane potential $\left(E_{M}\right)$. 
lines give values of $W_{2}$ at $0,1,2,3$ and 4 hours after the insertion of the electrode. The resting potentials calculated from these values are $76.48,88.59$, 82.21, 77.77 and $76.12 \mathrm{mV}$. The initial values (immediately after the insertion) of the resting potential are also shown in TABLE 1 . When the fluctuations of the resting potential exceeded about $15 \mathrm{mV}$ for four hours, the result was discarded (with some exceptions).

The time course of the change in the resting potential. The change in the resting potential during four hours of observation is illustrated in FIG. 4 with five instances. As shown in this FIG., the resting potential was maintained for four hours with some fluctuations. Results with $3 \mathrm{M}-\mathrm{NaCl}$ filled electrodes were similar to those with $3 \mathrm{M}-\mathrm{KCl}$ filled ones.

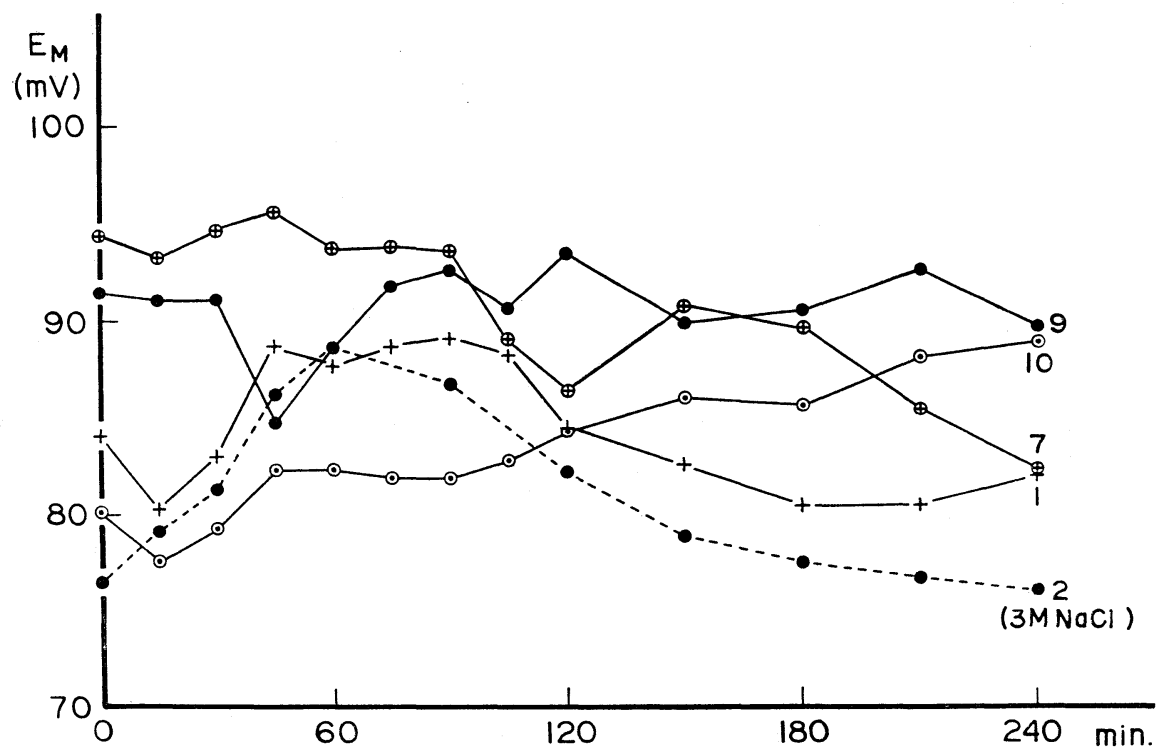

FIG. 4. Changes in resting potentials are plotted against time. Ordinate: resting potential $\left(E_{M}\right)$ in $\mathrm{mV}$. Abscissa: time after the electrode insertion in minutes. Numbers attached to each curve correspond to the experiment number in TABLE 1 and 2. Only in No. 2, 3M-NaCl filled micro-electrodes were used.

The average value of the resting potential. From values of successive thirteen measurements on one fiber for four hours, the mean value of the resting potentials was calculated. Mean values of ten fibers are shown in TABLE 2. They are ranging from $72.82 \mathrm{mV}$ to $100.60 \mathrm{mV}$. The average value of these ten fibers is $88.84 \pm 8.35 \mathrm{mV}$ (S. D.). This value coincides with the value obtained by NASTUK and HoDGKIN (1950), being higher than that of LING and GERARD (1949) and a little lower than those of ADRIAN (1956) and HODGKIN and HoROwICZ (1959). 
TABLE 2.

The mean value of $E_{M}$ 's obtained from thirteen successive measurements for four hours. The average value of mean values is $88.84 \pm 8.35 \mathrm{mV}$ (S. D.).

\begin{tabular}{c|c}
\hline Experiment number & Mean value $(\mathrm{mV})$ \\
\hline 1 & 84.59 \\
2 & 80.73 \\
4 & 88.38 \\
5 & 100.60 \\
7 & 90.91 \\
8 & 98.59 \\
9 & 90.64 \\
10 & 83.15 \\
11 & 97.95 \\
12 & 72.82 \\
\hline
\end{tabular}

\section{DISCUSSION}

By employing two micro-electrodes placed inside and outside a fiber and a current sensitive galvanometer, the resting potential could be obtained by the compensating method. In most cases reported by other workers (LING and GERARD, 1949; NASTUK and HodGKIN, 1950 ; AdrIAN, 1956; HodGKIN and HoroWICZ, 1959) resting potentials were not determined under such a condition as the present study. However, the difference between their values and those of the present paper are

not so large. A smaller value for resting potential recorded with external electrodes (RoThschUH, 1950) would be attributed to the short-circuiting effect of the external fluid.

In the present experiments, the resting potential stability was maintained for four hours in spite of some fluctuation, while RoTHschun found that the resting potential of a muscle in Ringer's solution decayed gradually (ROTHScHUH, 1950). It seemed to be due to the injury of the muscle. The fluctuation in the resting potential could not be explained in the present experiment.

A possibility for the fluctuation is that the "electrode potential" might change irregularly as the time goes on. In order to check this possibility, electrodes were left immersed in the Ringer for four hours during which the "electrode potentials" were measured at the same intervals as in the resting potential measurements. The results are shown in FIG. 5. When the "electrode potential" is relatively large, it decays gradually. While, when it is small, it does not change largely and irregularly. Thus the change in the "electrode potential" may not be the cause of the fluctuation of the resting potential.

According to HodgkIN and Horowicz (1959), the micro-electrode was not left inside the fiber for more than about two minutes and when it was necessary to observe it for longer periods, the potential was determined by successive impalements, but it was not usually possible to make more than about ten successive impalements in any one fiber. As it seemed impossible to do thirteen impalements on one particular fiber, the micro-electrode was left inside the fiber for four hours. In the same time it gave an advantage to avoid changing the state of electrode insertion for each impalement. Under 


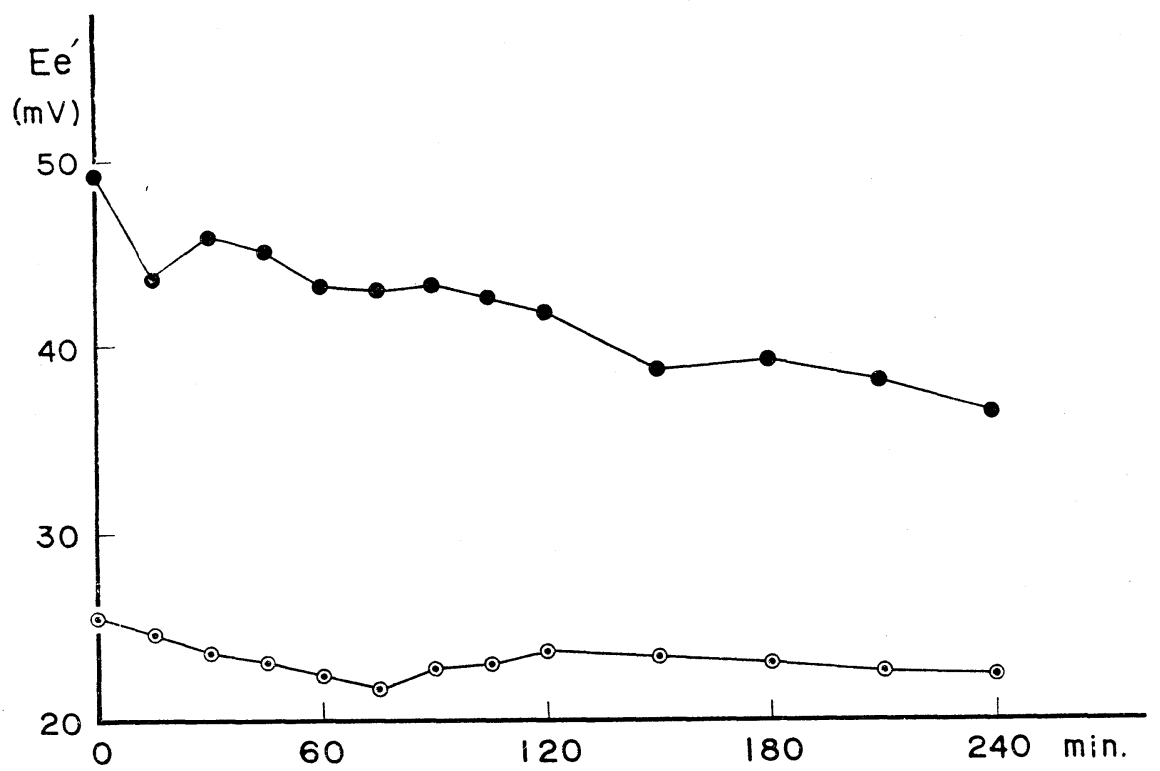

FIG. 5. Changes in "electrode potentials" are plotted against time. Ordinate: "electrode potential" in mV. Abscissa: time in minutes. Internal and external electrodes were immersed in Ringer's fluid for four hours during which "electrode potential" measurements were performed at the same intervals as in resting potential measurements. Two pairs of $3 \mathrm{M}-\mathrm{KCl}$ filled micro-electrodes with a resistance of $10 \mathrm{M} \Omega$ each were used.

such conditions, diffusion of $\mathrm{KCl}$ from the electrode tip might occur. KNUTssoN (1961) described that a baseline drift in long-lasting recordings of the resting potential was mainly due to the diffusion of ions at the site of the micro-electrode. He compensated the baseline drift and obtained the resting potential which was nearly constant for about an hour. The effect of the diffusion of $\mathrm{KCl}$ from the electrode tip during long-lasting observation of the resting potential is considered to be small (NASTUK and HoDGKIN, 1950) and not likely to be the cause of the above-mentioned fluctuation of the resting potential.

The most probable factor influencing the fluctuation seemed to be the changes in the condition of the electrode insertion probably owing to minute mechanical disturbances that could not be eliminated perfectly by shockabsorbing rubbers.

The electrode used by ADRIAN (1956) and HodGKIN and Horowicz (1959) had an electrode tip potential of several $\mathrm{mV}$; while the " electrode potential" in the present investigation (potential difference between two micro-electrodes) was rather high. The site of the "electrode potential" seems to be mainly between $3 \mathrm{M}-\mathrm{KCl}$ and Ag-wire. It is probable that the potential difference causing the "electrode potential" would exist at junctions between electrode 
tip and myoplasm of Ringer, 3M- $\mathrm{KCl}$ and $\mathrm{Ag}$-wire, and $\mathrm{Ag}$-wire and copper wire. The second is to be the most effective among them. It was tried to reduce the "electrode potential" by using similar electrodes, but it was impossible to reduce it to zero. Although a rather high "electrode potential" existed, the resting potential could be determined by subtracting or adding it from or to the measured potential.

\section{SUMMARY}

1. The resting potential of frog sartorius muscle fibers was determined by means of a compensating method using two micro-electrodes and a current sensitive galvanometer as a null instrument.

2. The mean value of resting potentials immediately after the insertion of the micro-electrode was $86.87 \pm 8.28 \mathrm{mV}$ (S. D.).

3 . The changes in the resting potential were observed for four hours and it was found that the resting potential was maintained for four hours although it was accompanied by some irregular fluctuation.

4. From thirteen potentiometric measurements within four hours, the mean resting potential of a fiber was calculated. The value ranged from $72.82 \mathrm{mV}$ to $100.60 \mathrm{mV}$ for ten different fibers and the average value was $88.84 \pm 8.35 \mathrm{mV}$ (S. D.).

I am greatly indebted to Professor S. SAKAмото for his kind leading and encouragement throughout the course of this work and to Professor A. TAKEUCHI for reading the manuscript. Also, I wish to thank Dr. K. Kurosawa for his help in carrying out the experiment, and Miss S. IKEDA for her valuable technical assistance.

\section{REFERENCES}

Adrian, R.H. (1956). The effect of internal and external potassium concentration on the membrane potential of frog muscle. J. Physiol. 133: 631-658.

Hodgkin, A.L. (1951). The ionic basis of electrical activity in nerve and muscle. Biol. Rev. 26 : 339-409.

HodgKin, A. L. (1958). Ionic movements and electrical activity in giant nerve fibres. Proc. Roy. Soc. B. $148: 1-37$.

Hodgkin, A.L. And Huxley, A.F. (1945). Resting and action potentials in single nerve fibres. J. Physiol. $104: 176-195$.

Hodgkin, A.L. And Horowicz, P. (1959). The influence of potassium and chloride ions on the membrane potential of single muscle fibres. J. Physiol. 148: 127-160.

Huxley, A.F. And Stämpfli, R. (1951). Direct determination of membrane resting potential and action potential in single myelinated nerve fibres. J. Physiol. 112: 476-495.

Knutsson, E. (1961). Effects of ethanol on the membrane potential and membrane resistance of frog muscle fibres. Acta physiol. scand. 52: 242-253.

Kohlrausch, F. (1927). Lehrbuch der Praktischen Physik. pp. 46-47. Leipzig: B. G. 
Teubner.

LiNG, G. AND GERARD, R. W. (1949). The normal membrane potential of frog sartorius fibers. J. cell. comp. Physiol. 34 : 383-396.

Nastuk, W.L. And Hodgkin, A. L. (1950). The electrical activity of single muscle fibers. J. cell. comp. Physiol. 35: 39-73.

Rothschun, K.E. (1950). Über elektrischen Entladungsvorgänge an der verletzten Skeletmuskelfaser und ihre Beziehungen zum Vorgang der Degeneration, der Regeneration und des Absterbens. Pflüg. Arch. ges. Physiol. 252: 445-467.

Sakamoto, S., Kita, H. And Kurosawa, K. (1961). Studies on the resting potential of frog sartorius fibers. J. Fhysiol. Soc. Jap. $23:$ 464-465. (Japanese)

Shanes, A.M. (1958). Electrochemical aspects of physiological and pharmacological action in excitable cells. I. The resting cell and its alteration by extrinsic factors. Pharmacol. Rev. 10:59-164.

STÄMPfl, R. (1954). A new method for measuring membrane potentials with external electrodes. Experientia, 10 : 508-509. 